\title{
Urinary System Part
}

National Cancer Institute

\section{Source}

National Cancer Institute. Urinary System Part. NCI Thesaurus. Code C13035.

Any component of the org ans involved in the creation and excretion of urine. 